embrace a chemical study of the most important secretions of the body. The test for hydrochloric and lactic acids in vomited matters, the recognition of the digestive ferments and the method of the determination of the activity of the same, and an analysis of the urine and bile, should be included. The student should be made perfectly familiar with the constituents of normal urine. In most medical schools the analysis of urine is limited to the detection of sugar, albumen and bile. Students with such training often mistake epithelial scales for casts, and pronounce every reducing substance found in the urine, sugar. I meet with mistakes of this kind frequently, and have known more than one physician to lose the confidence and respect of the patient and his friends by mistaking an epithelial scale for a cast. A physician is often pardoned for overlooking a serious trouble when it exists, but it is a sad mistake to tell some man that he has an incurable form of Bright's disease or diabetes, when nothing of the kind exists. The patient gets over his fright after a while, but he is not likely to forgive the doctor who has made the blunder.

I believe that analysis of urine should form a part of clinical instruction, but this work should be preceded by a scientific study of normal urine and the scientific methods of estimating the most important normal and abnormal constituents of the urine. The course in physiological chemistry will occupy not less than ten or twelve weeks.

5. Histology.-The medical man certainly must be able to recognize the various tissues of the body by their microscopical appearance. $\mathrm{He}$ must be acquainted with the methods of hardening specimens, making sections, mounting and staining the same. This knowledge can not be acquired from books or in the lecture room. Laboratory instruetion in this branch is a necessity. This knowledge can be gained in a course of six weeks.

6. Physiology.-All medical teachers admit the necessity of practical dissection in acquiring anatomical knowledge, while but few schools give practical courses in physiology. Notwithstanding this, it is certainly true that the medical man needs to employ his physiological knowledge quite as often as he does his anatomical learning. When such instruction is properly given we will have much more intelligence displayed in the practice of medicine. One needs to know the anatomy of the heart in order to detect valvular diseases of that organ, but the number of functional diseases of the beart which one is called upon to treat is certainly greater than that of structural diseases of the same organ, and yet the student in most of our schools has no practical instruction in the innervation of the circulating system. How many of us were able from knowledge gained in our undergraduate course to intelligently apply electricity to any part of the body, to mark out anæsthetic areas which would result from injury to or disease of any nerve, to intelligently interpret the reaction obtained in testing the knee reflex, to properly ascertain the degree of sensation in any muscle, to explain the relation between injury to the floor of the fourth ventricle and the glycogenic function of the liver: or in short, did we have any positive physiological knowledge other than a general idea of the processes of digestion, absorption and elimination? Do we not feel the want of this training in the work of every day? Should we not see to it that our students have this instruction? A six weeks' course in laboratory physiology will in my opinion be of great service.

7. Pathology.-The necessity of practical instruction in this branch will be admitted by all. Such a course should embrace both gross and minute pathology. The bungling way in which post-mortem examinations are of ten performed, and the little information which the medical man usually gets from such an examination, afford abundant evidence of the fact that gross pathology is too much neglected in our schools. Without microscopical pathology the determination of the nature of many growths is quiteimpossible. Let us give six weeks to the deadroom and laboratory courses in pathology.

To sum up I would say that the following laboratory courses are essential:

1. Analytical chemistry, 12 weeks.

2. Pracitical and surgical anatomy, 24 weeks.

3. Bacteriology, 10 to 12 weeks.

4. Physiological chemisty, 10 to 12 weeks.

5. Histology, 6 weeks.

6. Physiology, 6 weeks.

7. Pathology, 6 weeks.

This makes a minimum of 74 weeks. The greater part of this work should precede clinical instruction. Besides the above mentioned courses, therapeutics, including electro-theraputics, is now being taught in some schools largely by laboratory methods, and this tendency will grow.

Laboratory methods will soon largely modify clinical teaching. Amphitheatre clinics are giving way to bed-side and section instruction. Laparotomies and other capital operations are now made by the students in some of our schools on dogs. The surgeon as well as the chemist has his laboratory. The student delivers the alcohol baby from the rubber mother before he is permitted to enter the lying-in room. It is no longer necessary to spoil a hatful of human eyes before one becomes a skillful ophthalmologist.

\section{DISCUSSION OF DR. VAUGHAN'S PAPER.}

\section{BY BAYARD HOLMES, B.S., M.D.,}

SECRETARY COLLEGE OF PHYSICIANS AND SURGEONS, CHICAGO, ILL,

Mr. President and Gentlemen of the Association of Medical Colleges:-The paper of Dr. Vaughan, which has interested us so much, suggests great changes in medical education. During the past year my attention has been called to some of the details of laboratory work which must be faced by every one of you. Allow me to very briefly speak of some of the results of my thoughts and studies.

Laboratory rooms must be light and. roomy. Forty square feet of floor is the least amount which will accommodate a single student, and then only in the chemical laboratory. In all other laboratories at least sixty square feet of floor space, not including aisles, must be allowed each student. In the chemical laboratory students' desks may be placed twenty feet from the windows; in laboratories in which microscopes are to be used, fourteen feet is a maximum.

The ordinary medical class in the larger institutions ranges from one hundred down to thirty, and therefore the laboratory room should be, if lighted on both sides, not less than fifty by forty feet, and it may be lengthened but not widened. At the institution which I represent, our laboratory rooms were 
last winter twenty-five feet by sixty feet, lighted on laboratory work depends on the care with which one side and both ends; our largest class numbered these details are considered. One of the most imporninety-four, and it was necessary, therefore, except tant matters is the system of bookkeeping employed in chemistry and bacteriology, to divide the class by the curator in keeping track of the supplies. We into two sections and then crowd them. Our new lost at least two thousand dollars unnecessarily from laboratories are attached directly to the old ones and the neglect of this business-like forethought. Last are the same width (twenty-five feet), making each term we started out with a single man for curator. laboratory a room 160 feet long, lighted on one side The demonstrators furnished lists of material reand capable of accommodating eight students to quired for each of the nine laboratory courses which each ten feet of length. This gives us, besides the were conducted last term. A sufficient number of necessary reduction for aisles and preparation rooms, outfits were made up by the curator a month before accommodations for 120 students in, each laboratory. the term opened. On an appointed hour the students This seems like a large class for laboratory work. selected their desks in the laboratory in the order in So it is. And yet the fact that our laboratory teach- which they purchased their tickets. They went one ers are practicing physicians makes it necessary to by one to the store-room as their places were assigned economize their time. They are unable to give the and received each his outfit. In the outfit were two work the whole day, or every day in the week, and printed lists of the material contained. Each stuwe believe, supposing an unlimited supply, that brick, dent compared his invoice with the outfit, signed the

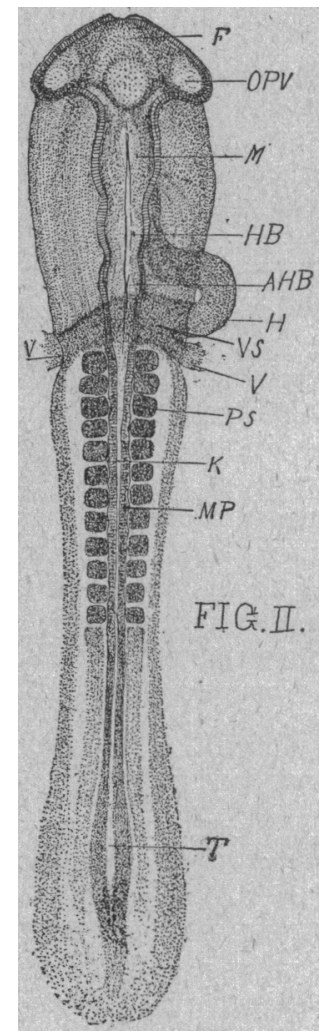

The Normal Embryo.

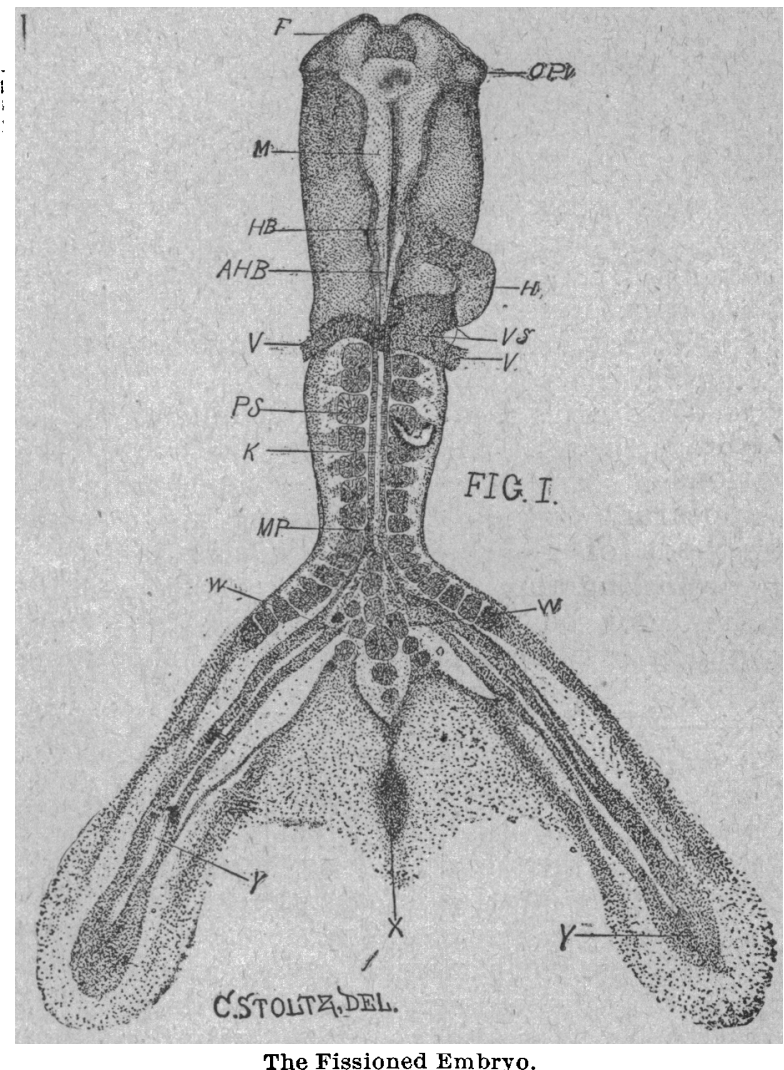

The Fissioned Embryo.

stone, glass and iron are cheaper than men. This|receipt on one invoice, left it with the curator, and large laboratory class necessitates great and even after locking the desk put his key in his pocket and elaborate system and unusually efficient teachers. Every man who can conduct a laboratory exercise creditably with a class of ten, will not be able to hold and instruct a class of seventy-five.

The order necessary requires such an arrangement of desks as will allow two sets of men to use each laboratory room. Our desks in the microscopical room have a flat surface $1 \frac{1}{2}$ by $3 \frac{1}{2}$ feet, of oiled white wood. There is a knee space two feet nearly, and two cupboards on the right, each locking with a Yale lock, and each eighteen inches square and two feet deep, in which are suitable drawers and shelves. The desks are built in pairs and the sides are stained white wood. Stools are provided that are about two inches higher than the ordinary chair and can be

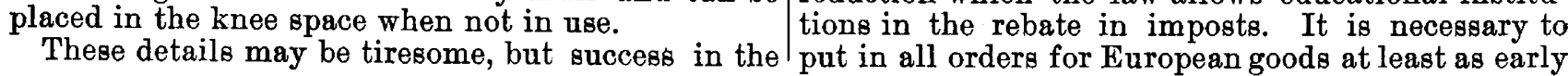


as March 1. In our laboratories we are using the Stolts and Mr. Osincup, selected out of the class, Leitz and the Bausch and Lomb microscopes. We each student opened his incubated egg, sketched and have now a sufficient number to give each man an removed his embryo, fixed, stained, imbedded, cut instrument. We urge students to provide themselves and mounted it. He made drawings representing the

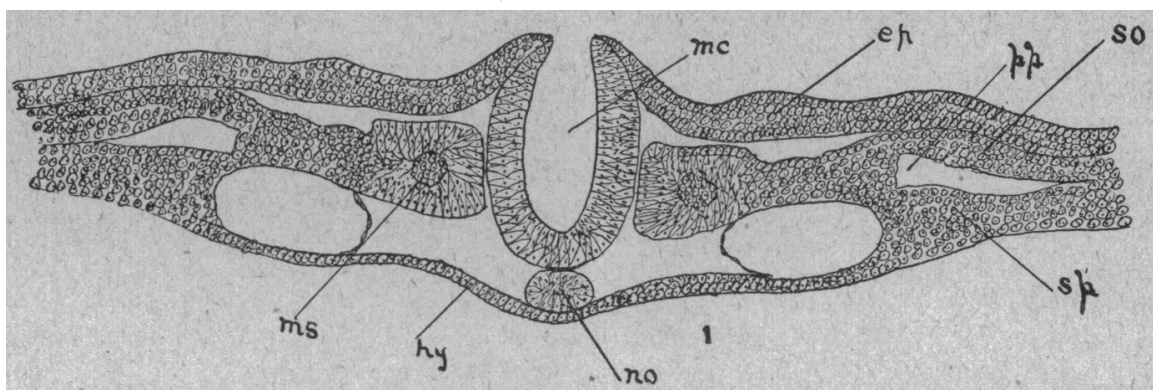

with microscopes, and many of them do, especially different portions, and was quizzed on the drawings the second year.

If I may be allowed the time, I should like to show you some drawings made last winter by second year

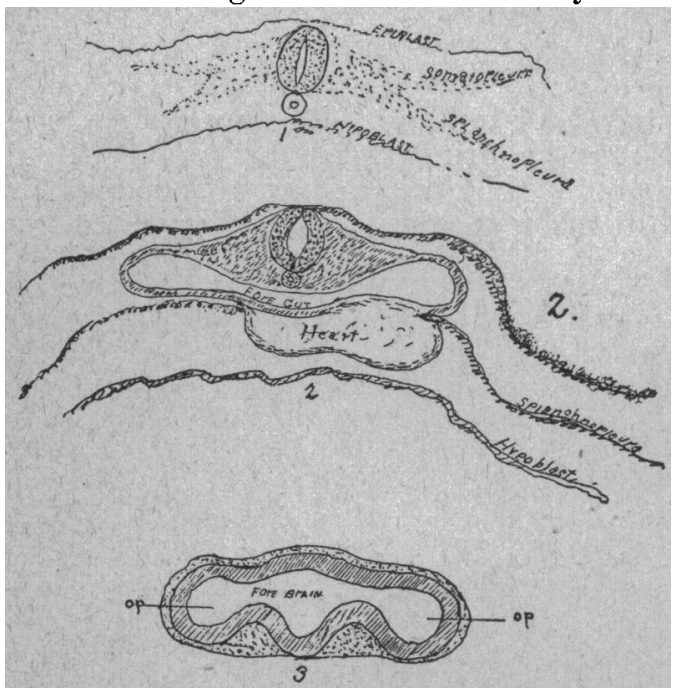
and the specimens under the microscope.

You will notice that in spite of the fact that there is a general impression among students that some cannot draw, there is not one disgraceful drawing in the lot, and there are at least two or three drawings from each student in a class of seventy-two. The class only studied the first four days of the embryo's development, so you will recognize all the parts.

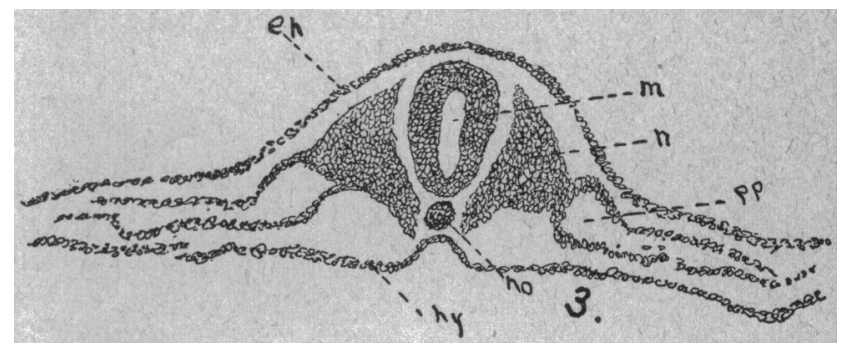

Let me call your attention especially to the drawing of the whole embryo by Mr. Stoltz. Each student made a sketch like this, but Mr. Stoltz, in examining men in the College of Physicians and Surgeons, in a large number of eggs, found one with an error of the laboratory of Dr. A. P. Ohlmacher, Professor of development which he has described in full in the Embryology and Biology. These 250 or more draw- Scalpel, the magazine published by the students of ings represent the work of every one of the class of the college. Both drawings are reproduced here to

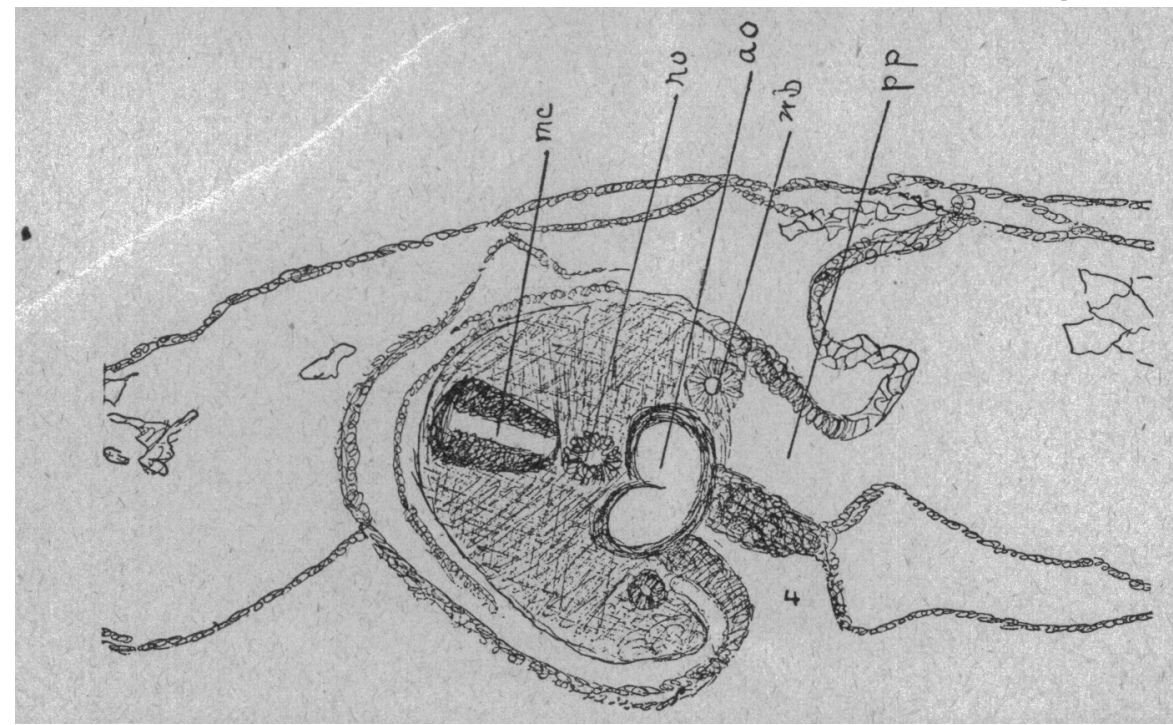

seventy-two students, and they were a part of the/show the best free-hand drawing, without the use of final examinations on that branch. Under the direc- a camera lucida or other projection device.

tions of Prof. Ohlmacher and his two assistants, Mr. Perhaps the only original departure made by the 
College of Physicians and Surgeons during the past than in the embryology. The drawings in all the year has been in the introduction of an extended laboratories are made on paper furnished at cost by course in Biology. This course really covers a course the College. It is of uniform size, 11 by $8 \frac{1}{2}$ inches, in comparative anatomy, a course in elementary or $8 \frac{1}{2}$ by $5 \frac{1}{2}$ inches. The drawings occupy a definite physiology, and a course in the histological study of portion of the sheet, leaving a margin of one inch the elements of mammalian structure. As a whole, all around, and a quarter of an inch more on the

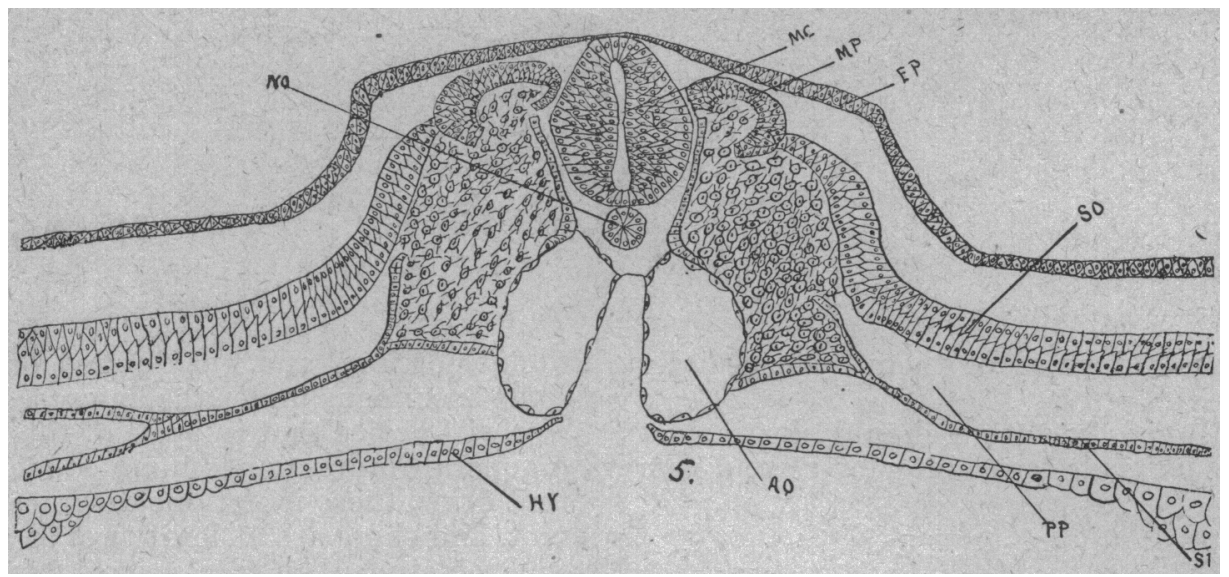

the course occupies ten hours a week, and has been left hand end for binding. It is impossible to show most successfully conducted by Prof. Ohlmacher. If this work on the printed page, but a few drawings it will not tire you too much, allow me to show you will be reproduced by the photographic process, much some 300 drawings made during the present spring reduced, in order to give a faint idea of the work.

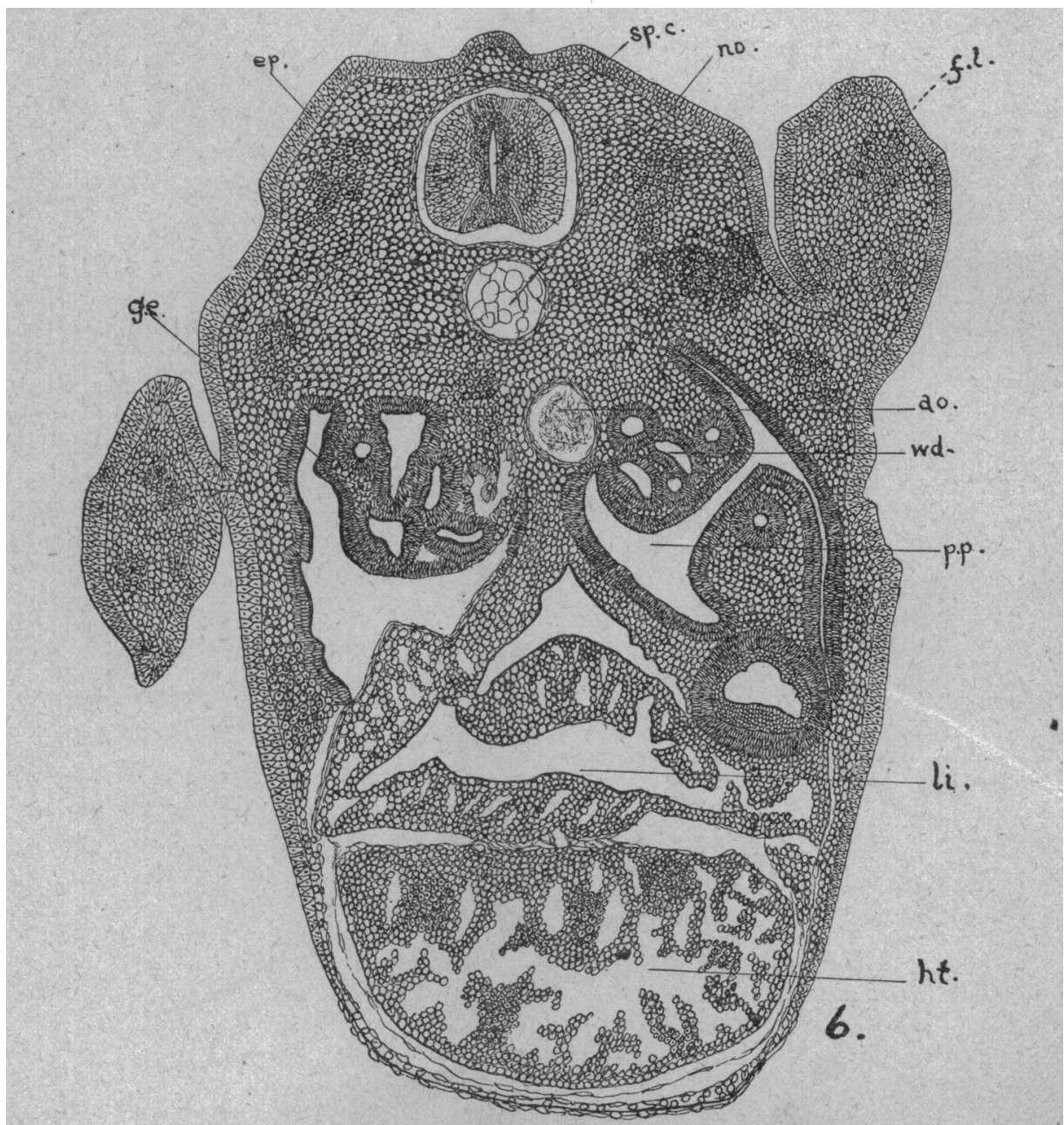

term by a class of twenty-two men who have just begun $\mid$ Some of the best drawings are in colors and cannot the study. The complete work of each man, as far as be reproduced at all, others are too fine to stand has been required, is before you. You will notice a reduction, and others have some shading which would greater difference in the mechanical execution here require too expensive a method of reproduction. 
Dr. Vaughan has given me one idea which is new, and that is of the position of bacteriology in the course. This branch has been placed in our schools in the third year, on account of its intimate connection with medicine and surgery, which fills the fourth year. There seems no reason why it should not th appear earlier in the course. Systematic bacteriology could certainly be placed in the second year. Still, I believe that its value to the student would be increased by associating it with pathological study as we have done.

In regard to the length of laboratory hours, several points must be considered. Microscopical laboratories cannot conflict, because we do not have enough microscopes to equip two laboratories at once. Our men cannot spare more than three hours at a time out of their practice, and therefore it has been found

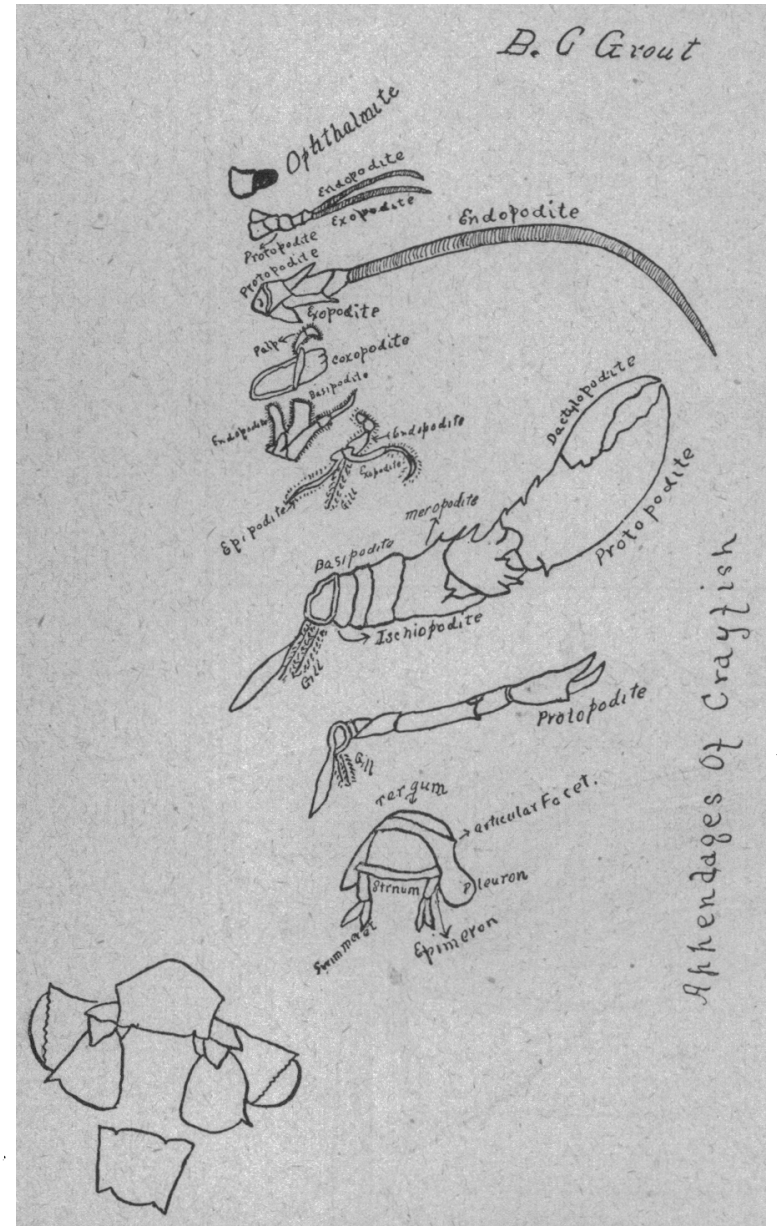

necessary with us to make the length of each laboratory exercise two hours. There is no doubt that, had we the entire time of our laboratory teachers at our disposal, it would be better to make the unit of the laboratory exercise three or four hours, as the essayist has suggested.

On account of the necessity of one laboratory exercise following another without intermission, and on account of the necessity of some preparation in each laboratory room before each exercise, we have concluded that it is necessary to provide at least two microscopical laboratories. This we have done, and you will see by the time card how our exercises follow one another, and what portion of the student's time in each year's work is occupied in lectures and recitations, in laboratory work and in clinics.
The introduction of laboratory work gives a new impetus to medical education in small cities. The work in this department can be done better, other things being equal, in small medical schools. I predict that these medical schools in small cities that adopt vigorous methods of laboratory teaching will rise to a prominence they could never have attained while medicine was taught by lectures and clinics alone.

The laboratory teaching will also make a change in the character of medical students. The farmer or butcher medical student cannot hold his knees fifteen or twenty hours a week under the laboratory table throughout a four-year course. He will give place to the educated young men of 20 , graduated now in such astounding numbers from the multiplying colleges all over the country, but especially the Central

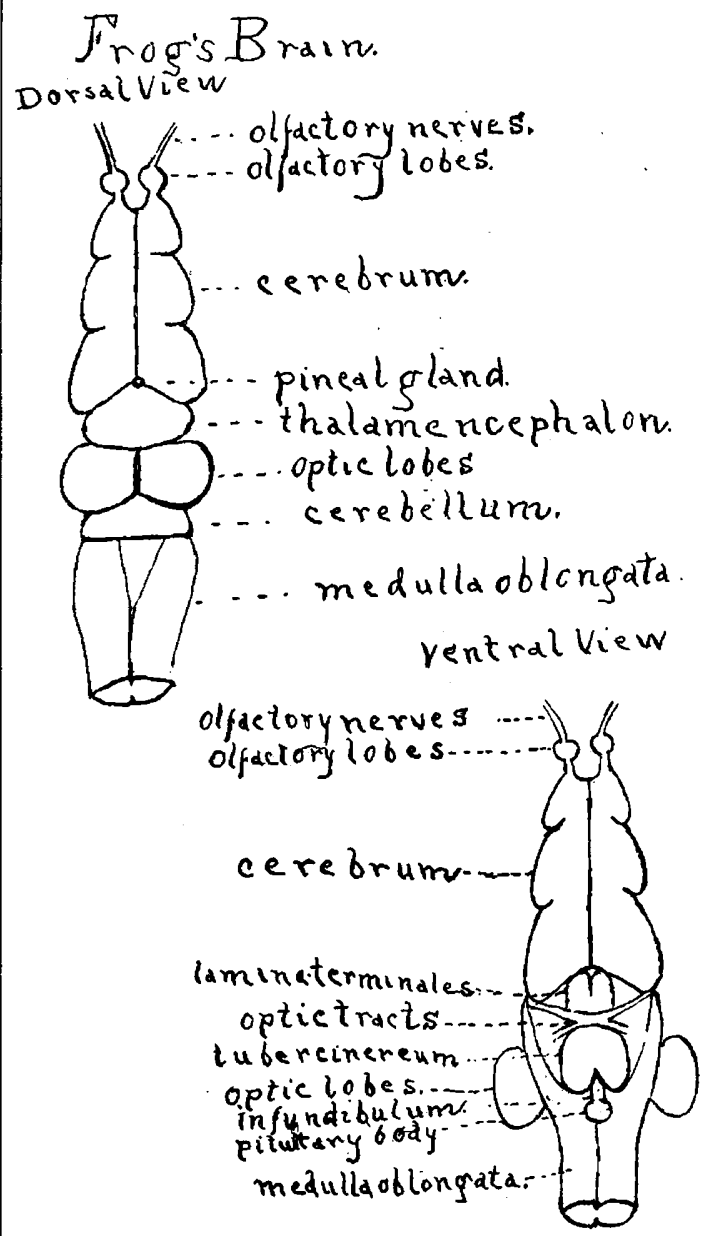

J. C. Flemming.

States. It should be our aim to secure these men, if we would have our efforts in medical education succeed.

Again, in order to have our laboratory work done in a constantly efficient manner, it must be done by the same men for a long time. This requires money, and more money than any but the largest schools can obtain from students. That is to say, laboratory work calls for endowment. Only a few State Universities pretend to support medical schools, and so far as I know only one of these, Minnesota, contributes liberally to the annual expenses of the medical department. It seems strange that the department of the university, which should in this country fur- 
nish one-fourth of the entire enrollment, should not ous stages of development. These drawings were have received even 2 per cent. of the endowment. It made on the paper described in India ink, being should be the concerted effort of this Association to copies of the class-room drawings which were first educate the generous public to a thorough under- made in a note book with lead pencil. No text-book standing of our deserts and our needs. was used in the work of embryology, the work being
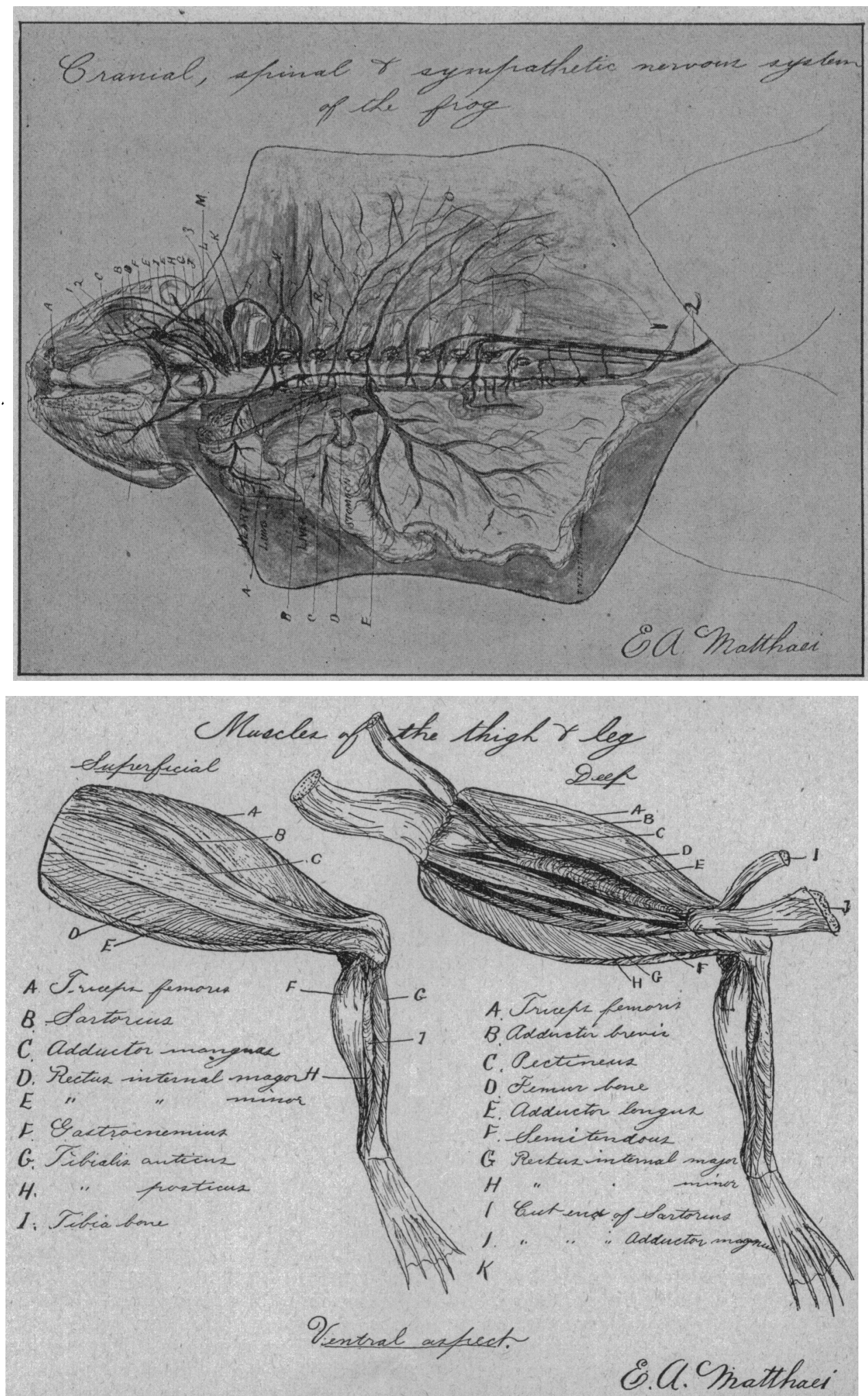

The accompanying figures, numbered $1,2,3,4,5$ and I guided by a few printed syllabi and by oral instruc6 , represent reproductions of embryological drawings tion. Hence the student had no illustration of the by several of the students in the class. They are all object he studied, save the picture his mind conceived. drawings of cross sections of embryo chicks of vari- We may, therefore, take these drawings as represent- 
ing the student's individual conception. The lettering region and one through the fore brain of a 36 -hours of the various parts is made uniform only for the chick, all from the same embryo. Fig. 3, from an sake of easy comparison.

Fig. 1 was drawn by Mr. J. F. Adams from a section Fulton. Fig. 4 shows the amniotic folds and amniotic of the tail end of a 36-hours chick. It shows veryl cavity very clearly, and was drawn by Mr. G. A.

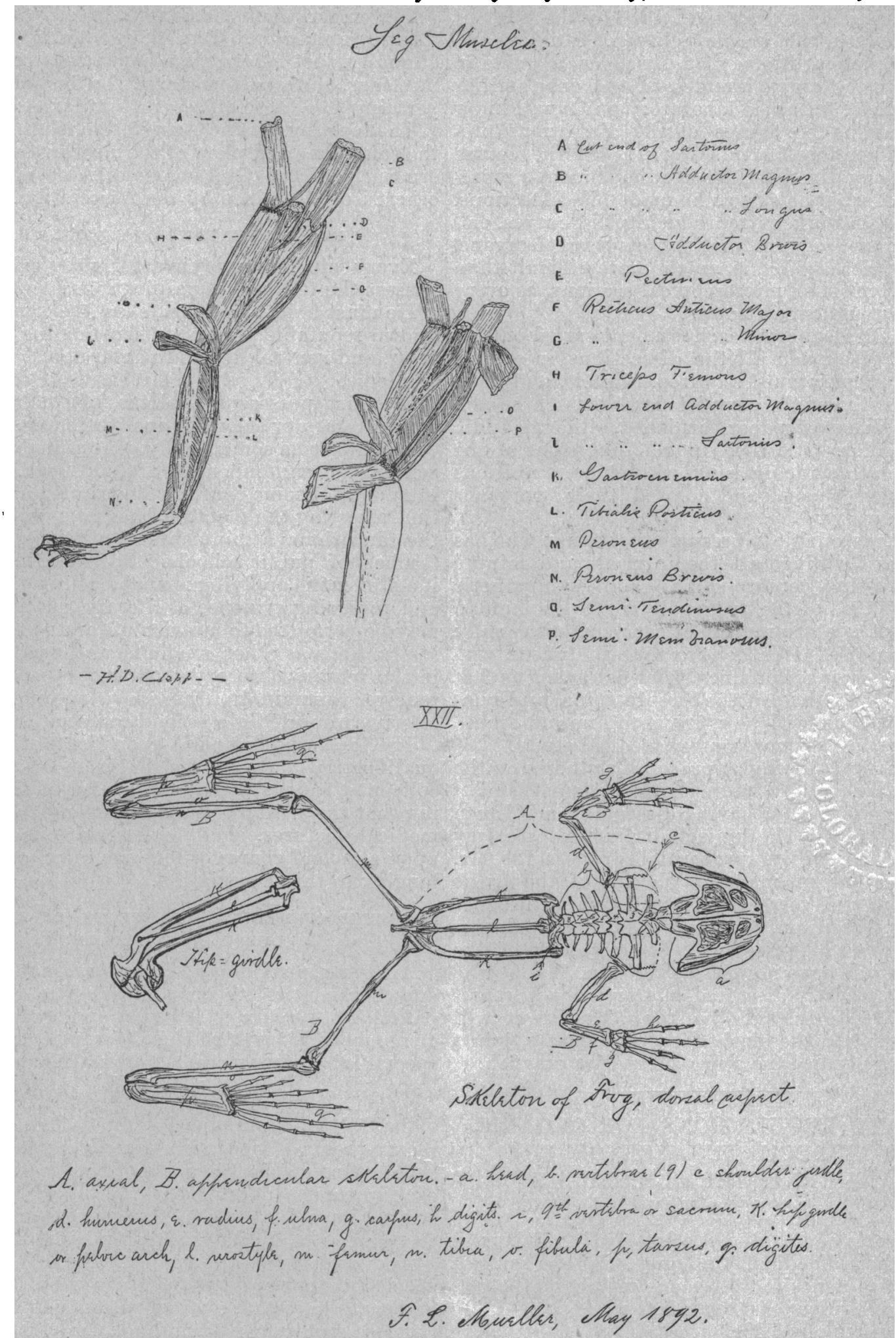

clearly the primitive germinal layers, splitting of the Hibbert. Fig. 5 is from a section through the hind mesoblast, mesoblastic somites, notochord and medul- end of a 3-days chick, by Mr. R. H. Herrold. Fig. lary canal not completely closed. Fig. 2 represents 6 was drawn from a section of a 5-days chick, by Mr. three drawinge by Mr. $\Theta$. B. Monosmith, showing a J. J. Pierron, and shows the budding of the fore section through the tail end, one through the heart/limbs, the development of the heart, liver, urogenital system, etc. 
To anyone who has had experience in this kind of work it must be evident that many hours of painstaking labor have been spent in producing some of these drawings.

The few drawings of the spring class in biology here reproduced speak for themselves. They are copies of note book drawings made by the student as he dissected the animal chosen. Huxley and Martin's Practical Biology was used as a guide in the work on the crayfish and frog, and one familiar with this most valuable laboratory guide will know that it contains no figures of the dissections prescribed. Therefore, in this work, as in the course in embryology, the drawings are the student's representation of what he saw as he made his dissections. Moreover, this work of reproducing the curves, elevations and depressions, distinctions between organs, etc., of the whole object, is much more difficult than the reproduction of microscopical sections, as every scientific draughtsman knows.

In the biological class each student caried out his own work. He made all the dissections, injections and other preparations required, himself, and then made a drawing of the completed work which he copied on the sheets of paper furnished, either in India ivk or in color. It will be noted that some of the work is plain outline drawing, while more ambitious students have shaded and colored their drawings most artistically.

Is it not reasonable to presume that a man who has dissected and verified all the intricate and minute relations of the cerebro-spinal and sympathetic nervous systems of the frog will go to his human subject with a determination of carrying out equally exacting studies? We believe that a student who has by his own labor produced such a drawing as that made by Mr. Matthaei of the cerebro-spinal and sympathetic systems, will be a credit to himself and to his teachers in any more purely medical study.

Will not Mr. Fleming approach his studjes on the human brain with a more lively interest and a broader foundation for having dissected and drawn this frog's brain? The subject of human osteology will lose some of its proverbial dryness for Mr. Mueller since he has made his picture of the frog's skeleton and since he became familiar with the bones of the frog's cranium, some of which are no larger than the letters of this type. The myology of the human leg will have no terrors for Mr. Clapp who has so scientifically dissected and artistically represented the leg muscles of the frog. Mr. Grout will better appreciate the mechanism of a man's joints from having studied the appendages of a crayfish.

\section{RULES AND REGULATIONS FOR ORGANIZA- TION AND MAINTENANCE OF THE SOUTHERN MEDICAL COLLEGE ASSOCIATION.}

This Association shall be composed of delegates from Southern Medical Colleges, whose Faculties have signified a desire to become members thereof, signed these rules of organization, and paid the membership fee of $\$ 5.00$.

The objects of the Association are to cultivate closer and more intimate relation between medical colleges and to elevate the standard of medical education by requiring a more thorough preliminary raining and an increased length of medical study. The Association shall be composed of one or more from each Medical College, belonging thereto, who shall be elected annually by their respective faculties. Each college shall be entitled to one vote in the transactions of the Assnciation.

The officers shall consist of a President, Vice-President, Secretary and Treasurer, who shall be elected annually, just before the adjournment of the annual meetings, and shall perform the respective duties, pertaining to these offices in similar organizations.

The meetings of the Association shall be held at the same time and place of the meetings of the Southern Surgical and Gynecological Association, unless otherwise determined by the Association.

REQUIREMENTS FOR MATRICULATION.

Every student applying for matriculation must possess the following qualifications:

He must hold a certificate as the pupil of some known reputable physician, showing his moral character, and general fitness to enter upon the study of medicine.

He must possess a diploma of graduation from some literary or scientific institution of learning. or certificate from some legally constituted high school, general Superintendent of State Education or Superintendent of some country Board of Public Education, attesting the fact that he is possessed of at least the educational attainments required of second grade teachers of public schools. Provided, however, that if a student so applying is unable to furnish the above and foregoing evidence of literary qualifications, he may be permitted to matriculate and receive medical instructions as other students, and qualify himself in the required literary departments, and stand his required examination as above specified, prior to offering himself for a second course of lectures.

The foregoing diploma or certificate of educational qualifications, attested by the Dean of the medical college attended, together with a set of tickets showing that the holder has attended one full course of medical lectures, shall be essential to attendance upon a second course of lectures in any college belonging to this Association.

BRANCHES OF MEDICAL SCIENCE TO BE INCLUDED IN COURSE OF INSTRUCTIONS.

Anatomy, physiology, chemistry, materia medica and therapeutics, theory and practice of medicine, pathology, surgery, obstetrics and gynecology, hygiene, medical jurisprudence,(forensic medicine) and special laboratory work as hereinafter provided.

QUALIFICATIONS FOR GRADUATION.

Candidates for graduation in addition to the usual requirements of medical colleges, must have attended three courses of lectures of not less than six months each in three separate years;

Must have dissected in two courses, and attended two courses of clinical or hospital instructions,

And must have attended one course in each of the special laboratory departments to-wit: 1. Histology and bacteriology. 2. Chemistry. 3. Operative surgery.

These requirements shall not apply to any student who has received a course of medical lectures prior to September 1, $1893 . \quad$ M. T. BRIGGS, J. B. Marvin, J. S. CaIn, Com'tee. 